\title{
Functional role of selenium-fortified yogurt against aflatoxin-contaminated nuts in rats
}

\author{
Amnah M. A. Alsuhaibani* (10)
}

\begin{abstract}
Background: Aflaxions are a group of chemically toxic fungal metabolites produced by species of the genus Aspergillus. Nuts can be contaminated by fungi, resulting in the production of mycotoxins. The present study was performed to investigate the ability of selenium-fortified yogurt to counteract the adverse effects of consuming $3 \%$ experimental nuts (pistachios, cashews, walnuts, almonds and hazelnuts) contaminated with aflatoxins in experimental rats. First, the total aflatoxins concentrations were estimated in fresh nuts, and in nuts after 6 months of storage, and seleniumfortified yogurt was prepared. Rats were classified into a negative control group (fed a standard diet with a 3\% mixture of fresh safe nuts), a positive control group (fed a standard diet with a 3\% mixture of nuts contaminated with aflatoxins after storage at $25^{\circ} \mathrm{C}$ for 6 months) and treated groups that fed on pistachios with selenium-fortified yogurt, cashews with selenium-fortified yogurt, walnuts with yogurt fortified with selenium, almonds with selenium-fortified yogurt and hazelnuts with selenium-fortified yogurt (fed a standard diet with 3\% individual nuts contaminated with aflatoxins and $160 \mathrm{ml} / \mathrm{kg}$ body weight of selenium-fortified yogurt daily through a stomach tube).
\end{abstract}

Results: The negative effects of aflatoxins on weight gain and food intake were reversed by selenium-fortified yogurt. This yogurt also led to a significant decrease in serum cholesterol, TG, LDLc, VLDLc, total lipids, phospholipids, glucose and atherogenic indexes (CHO/HDLc and LDLC/HDLc) and an increase in serum HDLc, haemoglobin, PCV, liver TG and glycogen at $p<0.05$. In addition, the study showed a significant decrease in liver cholesterol and total lipids compared to the positive control rat group, which consumed 3\% mixed nuts contaminated with aflatoxins and simultaneously restored these parameters to be close to those in the control group. The results were corroborated by histopathological examination of the liver and kidneys.

Conclusions: The most prominent conclusion is that selenium-fortified yogurt reduces side effects from consumption of nuts contaminated with aflatoxins. It is recommended to consume functional selenium-fortified yoghurt for its nutritional values and for alleviating the harmful effect of aflatoxins in nuts.

Keywords: Nuts, Aflatoxins, Lipids pattern, Selenium, Yogurt, Liver, Kidney, Rats

\section{Background}

Aflatoxins (AF) are mycotoxins produced by Aspergillus flavus and Aspergillus parasiticus that affect livestock and humans and occur as natural contaminants in foods containing peanuts and corn meal [1]. Aflatoxin-contaminated foods (i.e., grains and nuts) are more commonly

*Correspondence: amalsuhaibani@pnu.edu.sa

Nutrition and Food Sciences Department, Home Economic College,

Princess Nourah Bint Abdulrahman University, Riyadh, Saudi Arabia observed in tropical regions, including sub-Saharan Africa and Southeast Asia [2]. There are four major types of aflatoxins (B1, B2, G1 and G2), all of which are carcinogenic, teratogenic, hepatotoxic, immunosuppressive and capable of inhibiting several metabolic systems, causing liver, kidney and heart damage [3]. Aflatoxin B1 (AFB1) is the most frequently occurring and most toxic. Its toxic effects may be due to the generation of free radicals resulting in lipid peroxidation, which is a damaging process for all biological systems since cell membranes 
contain fatty acids that serve as substrates for free radical oxidation [4,5]. Although the liver is the principal target organ for AF, the kidney and testis can also be affected following dietary and inhalational exposure. The majority of the toxin is metabolized in the liver, where AFB1 is converted by hepatic cytochrome P450 enzymes into the reactive and electrophilic exo-AFB1-8,9-epoxide. This highly unstable intermediate quickly reacts with DNA, RNA and proteins, which leads to cell death $[6,7]$. Chronic AFB1 exposure, especially in combination with hepatitis B infection, severely increases the risk of hepatocellular carcinoma in humans [8].

Yogurt contains many probiotic bacteria, including Lactobacillus bulgaricus and Streptococcus thermophilus, which provide benefit through existing as microflora in the intestines and by acting directly on bodily functions such as digestion and immunity $[9,10]$. Fermented dairy products contain live lactic acid bacteria, and these bacteria and their metabolites have been shown to modulate the immune response in animals, suppress carcinogenesis in rodents, inhibit the activity of enzymes related to carcinogenesis and bind mutagenic and carcinogenic heterocyclic amines. The fermentation process leads to a reduction in the lactose content of the milk and an increase in lactic acid $[11,12]$. Yogurt has been documented as therapeutic for a variety of disorders including lactose intolerance, which is ameliorated due to a reduced cholesterol level, alimentary tract diseases, constipation, diarrhoea, gastroenteritis, indigestion, intoxication, hypercholesteremia, kidney and liver disorders and cancer [13-15].

Selenium is essential for the immune system in both animals and humans and has emerged as an important element for dietary protection from various toxic agents $[16,17]$. Moreover, selenium has been reported to be protective against the toxic effects of aflatoxins. Early studies revealed that selenium can modify the disease process and counteract AFB1-induced adverse effects, such as impaired development and histopathological lesions in immune organs [18]. Selenium might enhance the conjugation of aflatoxins by increasing excretion of the aflatoxins and by preventing the formation of AFB1DNA adducts. The protective effect of selenium is mediated through a cellular mechanism related to glutathione detoxification pathways [19-21].

The present study uses a rat model to investigate whether selenium-fortified yogurt can counteract the adverse effects resulting from consuming nuts contaminated with aflatoxins.

\section{Methods}

Nuts

Five kilograms of most edible nuts and more susceptible to mould growth (pistachios, cashews, walnuts, almonds and hazelnuts) was obtained from a local market in Riyadh, Saudi Arabia.

\section{Chemicals}

All materials used in this experiment were of analytical grade. BioMerieux kits were purchased from Alkan Co. for Chemicals and Biodiagnostics. Selenium was obtained from Sigma Chemical Company (St. Louis, MO, USA).

\section{Probiotic bacteria}

Cow milk was purchased from a local market in Riyadh, Saudi Arabia. Lactobacillus delbrueckii bulgaricus $\mathrm{CH}-2$ and Streptococcus thermophilus ST-36 were obtained from Chr. Hansen's Laboratory in Rich, Denmark.

\section{Experimental animals}

Seventy adult male white Sprague-Dawley strain albino rats, $130 \pm 10 \mathrm{~g}$, were purchased from the experimental animals centre in the Research Centre in Prince Sultan Military Medical City, Riyadh. Rats were housed in groups in wire cages under the normal laboratory conditions and fed a standard diet for a week as an adaption period. Food and water were provided ad libitum. Ethical guidelines were maintained in animal handling during the study, and permission was obtained from the relevant department.

\section{Standard diet}

The standard experimental diet was composed of corn starch $(598 \mathrm{~g} / \mathrm{kg})$, casein $(200 \mathrm{~g} / \mathrm{kg})$, soybean oil $(100 \mathrm{~g} /$ $\mathrm{kg})$, vitamins mixture $(10 \mathrm{~g} / \mathrm{kg})$, salts mixture $(40 \mathrm{~g} / \mathrm{kg})$, cellulose $(50 \mathrm{~g} / \mathrm{kg})$ and choline chloride $(2 \mathrm{~g} / \mathrm{kg})$ according to the Second Report of the American Institute of Nutrition [24].

\section{Preparation of yogurt}

Lactobacillus delbrueckii subsp. bulgaricus $\mathrm{CH}-2$ was cultivated in $25 \mathrm{ml}$ of MRS broth medium at $37^{\circ} \mathrm{C}$ for $24 \mathrm{~h}$. Streptococcus thermophilus ST-36 was grown in $25 \mathrm{ml}$ of M17 broth at $40{ }^{\circ} \mathrm{C}$ for $24 \mathrm{~h}$. The whole milk was boiled to reduce its volume by approximately $20 \%$, then heated at $90{ }^{\circ} \mathrm{C}$ for $5 \mathrm{~min}$, cooled to $42{ }^{\circ} \mathrm{C}$ and inoculated with $1 \%$ of Lactobacillus delbrueckii subsp. bulgaricus $\mathrm{CH}-2$, Streptococcus thermophilus and $1 \mathrm{~g}$ of selenium/litre of milk and then incubated at $40{ }^{\circ} \mathrm{C}$ for approximately $4 \mathrm{~h}$ until coagulation. The yogurt samples were stored at $5 \pm 1{ }^{\circ} \mathrm{C}$ for 2 days [25].

\section{Sensory evaluation}

The selenium-fortified yogurt was evaluated for its sensory characteristics including aroma, taste, texture, colour and overall acceptability. A total of 20 trained 
voluntary panellists were involved in the hedonic test. The results are represented by the following scores: excellent, 9-10 (90-100\%); very good, 8-9 (80-90\%); good, 6-7 (60-70\%); fair, 4-5 (40-50\%); poor, 2-3 (20-30\%); and very poor, $0-1(0-10 \%)$.

\section{Estimation of aflatoxins}

Nuts were crushed separately, and equal amounts of ever crushed nut were mixed to estimate the total aflatoxins at zero time of storage (fresh) as nuts can be naturally infected with Aspergillus fungi that produce aflatoxins [22, 23]. Individual raw experimental nuts and mixture nuts were stored separately in glass dishes at $25^{\circ} \mathrm{C}$ and $70 \%$ relative humidity for 6 months. The total aflatoxins after 6 months of storage were estimated. According to these aflatoxin levels, the biological study was designed.

\section{Grouping of rats and experimental design}

Animals were divided into seven groups as follows:

- The negative control group was fed a standard diet with a $3 \%$ fresh mixture of the five experimental nuts (zero time of storage, safe nuts).

- The positive control group was fed a standard diet with a 3\% mixture of five nuts contaminated with aflatoxins after storage at $25^{\circ} \mathrm{C}$ for 6 months.

- The pistachio with selenium-fortified yogurt rat group was fed a standard diet with $3 \%$ pistachios contaminated with aflatoxins after storage at $25{ }^{\circ} \mathrm{C}$ for 6 months and $160 \mathrm{ml} / \mathrm{kg}$ body weight daily of selenium-fortified yogurt through a stomach tube [25].

- The cashew with selenium-fortified yogurt group was fed a standard diet with $3 \%$ cashews contaminated with aflatoxins and $160 \mathrm{ml} / \mathrm{kg}$ body weight daily of selenium-fortified yogurt through a stomach tube.

- The walnut with selenium-fortified yogurt group was fed a standard diet with 3\% walnuts contaminated with aflatoxins and $160 \mathrm{ml} / \mathrm{kg}$ body weight daily of selenium-fortified yogurt through a stomach tube.

- The almond with selenium-fortified yogurt group was fed a standard diet with $3 \%$ almonds contaminated with aflatoxins and $160 \mathrm{ml} / \mathrm{kg}$ body weight daily of selenium-fortified yogurt through a stomach tube.

- The hazelnut with selenium-fortified yogurt group was fed a standard diet with $3 \%$ hazelnuts contaminated with aflatoxins and $160 \mathrm{ml} / \mathrm{kg}$ body weight daily of selenium-fortified yogurt through a stomach tube.

After completion of the experimental period (60 days), rats were fasted overnight and killed to obtain blood, kidneys and liver.

\section{Biological determination}

Biological evaluation of the different diets was carried out by determination of the initial body weight, body weight gain (BWG\%) and feed intake and calculation of the feed efficiency ratio (FER) by dividing the daily body weight gain by the daily feed intake. Serum cholesterol $(\mathrm{CHO})$, triglycerides (TG), high-density lipoprotein cholesterol (HDLc) and total lipids (T. lipids) were determined by enzymatic colourimetric methods [26-28]. Very lowdensity lipoprotein cholesterol (VLDLc) was calculated as TG/5, and low-density lipoprotein cholesterol (LDLc) was calculated as total cholesterol minus HDLc + VLDLc [29]. Blood haemoglobin (HG), packed cell volume (PCV) and glucose were estimated in heparinized blood. Atherogenic indexes ( $\mathrm{CHO} / \mathrm{HDLc}$ and LDLc/HDLc) and phospholipids were calculated. Livers were immediately perfused with $50-100$ of ice-cold $0.9 \% \mathrm{NaCl}$ solution for estimation of liver cholesterol, triglycerides, total lipids and glycogen. Fresh portions of liver and kidney from every rat were immersed in $10 \%$ neutral buffered formalin for future histopathological examination. The fixed specimens were later trimmed, washed and dehydrated in ascending grades of alcohol, cleared in xylene, embedded in paraffin, sectioned at 4-6 $\mu \mathrm{m}$ thickness and stained with haematoxylin and eosin before microscopic examination. In addition, Masson's trichrome and Sudan Black B methods were also used to stain collagen tissues and to demonstrate changes in fatty tissues [30].

\section{Precautions with aflatoxins}

Laboratory surfaces were cleaned with $1 \%$ sodium hypochlorite. Suitable protective clothes such as laboratory masks, coats and gloves were worn. All laboratory instruments were washed with $10 \%$ sodium hypochlorite before cleaning or discarding and after use. Aflatoxins were deactivated by autoclaving in the presence of ammonium and by treatment with hypochlorite [31,32].

\section{Statistical analysis}

Collected data are presented as the mean \pm SD and statistically analysed using one-way analysis of variance (ANOVA) with the level of significance indicated at $p<0.05$. Student's $t$ test was used for evaluating the significance of paired observations [33].

\section{Results and discussion}

The total aflatoxin concentration was $4.97 \mu \mathrm{g} / \mathrm{kg}$ in the mixture of fresh nuts at zero time of storage, which is considered to be safe according to the European Union standard, Iran standard and Australia New Zealand Food Standards Code. The total aflatoxins in the mixed nuts after 6 months of storage were $24.84 \mu \mathrm{g}$ was $24.84 \mu \mathrm{g} /$ $\mathrm{kg}$, which is not considered safe by the European Union 
standard, Iran standard, and Australia New Zealand Food Standards Code. The estimated total aflatoxins were $23.25,23.66,22.07,26.02$ and $28.6 \mu \mathrm{g} / \mathrm{kg}$ in the pistachios, cashews, walnuts, almonds and hazelnuts, respectively. According to these aflatoxin levels, the biological study was designed.

In overall acceptability, the fresh selenium-fortified yogurt was rated very good $(80-90 \%)$ and the commercial brand was rated excellent (90-100\%; Table 1). Selenium-fortified yogurt was acceptable to the panellists as indicated by their mean score for overall acceptability.

The nutritional and therapeutic benefits of the consumption of dairy products containing live Lactobacillus acidophilus as a food or supplement have been the focus of studies for the last two decades [34-36]. However, the production of high-quality fermented milk products containing these probiotic bacteria is a major challenge due to specific attributes of the bacteria such as rapid acid production from lactose and development of suitable quantities of volatile compounds such as diacetyl and acetaldehyde [37]. Selenium is an essential element in almost all biological systems. Although significant attention has been placed on the organoleptic characteristics of selenium-fortified yogurt, little emphasis has been placed on consumer acceptability and preference of the finished product. To enhance the consumption of yogurt, consumer satisfaction must be balanced with cost-effectiveness and health benefits [38].
The effect of consumption of aflatoxin-contaminated nuts on rat body weight, food intake and FER is illustrated in Table 2. The positive control rat group that consumed 3\% mixed nuts contaminated with aflatoxins showed a significant decrease in body weight and FER at $p<0.05$ compared to the negative control rat group that consumed 3\% safe fresh mixed nuts. Consumption of 3\% pistachios, walnuts, almonds, or hazelnuts contaminated with aflatoxins in addition to selenium-fortified yogurt produced body weight and feed intake that were within normal values of the negative control group, along with a significant decrease in the feed efficiency ratio compared to the negative control group and a significant increase in this value compared to that of the positive control rat group. Consumption of 3\% cashews contaminated with aflatoxins in addition to selenium-fortified yogurt by experimental rats produced insignificant changes to body weight, feed intake and FER compared to the negative control group.

Aflatoxin B1 accumulates in the liver to very high concentrations and is metabolized through microsomal enzymes by hydroxylation, hydration, demethylation and epoxidation reactions. Aflatoxin B1 causes damage to the liver and adversely affects key metabolic pathways of carbohydrates, proteins and lipids [6,39]. Aflatoxin ingestion can also lead to body weight loss by changing the activities of digestive enzymes, causing malabsorption syndrome, characterized by steatorrhea as well as hypocarotenoidemy, and lowering the bile, pancreatic

Table 1 Sensory evaluation of selenium-fortified yogurt compared to the commercial brand

\begin{tabular}{llllll}
\hline Attribute & Aroma & Taste & Texture & Colour & Overall acceptability (\%) \\
\hline Selenium-fortified yogurt & $8.2 \pm 1.52$ & $8.4 \pm 1.24$ & $8.7 \pm 1.33$ & $8.5 \pm 1.55$ & $33.8 \pm 3.20(84.5 \%)$ \\
Commercial yogurt & $9.1 \pm 1.62$ & $9.2 \pm 1.73$ & $9.3 \pm 1.54$ & $9.2 \pm 1.65$ & $36.8 \pm 3.26(92 \%)$ \\
\hline
\end{tabular}

Table 2 Body weight, food intake and feed efficiency ratio in the experimental rat groups

\begin{tabular}{|c|c|c|c|c|}
\hline \multicolumn{5}{|l|}{ Groups } \\
\hline Negative control consumed $3 \%$ mixed fresh nuts & $130.77 \pm 5.50 \mathrm{a}$ & $120.2 \pm 5.80 a$ & $15.11 \pm 1.30 \mathrm{a}$ & $0.132 \pm 0.003 a$ \\
\hline $\begin{array}{l}\text { Positive control consumed 3\% mixed nuts contaminated with } \\
\text { aflatoxins }\end{array}$ & $131.87 \pm 5.50 \mathrm{a}$ & $100.21 \pm 8.99 d$ & $14.50 \pm 1.69 a$ & $0.114 \pm 0.002 c$ \\
\hline \multicolumn{5}{|c|}{ Rat groups consumed 3\% pistachios, cashews, walnuts, almonds and hazelnuts contaminated with aflatoxins } \\
\hline Pistachios with selenium-fortified yogurt & $131.91 \pm 5.44 a$ & $110.33 \pm 4.35 a$ & $14.90 \pm 2.53 a$ & $0.123 \pm 0.004 b$ \\
\hline Cashews with selenium-fortified yogurt & $131.71 \pm 5.44 a$ & $112.45 \pm 5.40 a$ & $14.09 \pm 2.49 a$ & $0.133 \pm 0.003 a$ \\
\hline Walnuts with selenium-fortified yogurt & $131.61 \pm 5.44 a$ & $113.43 \pm 3.85 a$ & $15.01 \pm 2.30 \mathrm{a}$ & $0.125 \pm 0.004 b$ \\
\hline Almonds with selenium-fortified yogurt & $131.53 \pm 5.44 a$ & $115.39 \pm 3.50 a$ & $15.11 \pm 1.90 a$ & $0.127 \pm 0.005 b$ \\
\hline Hazelnuts with selenium-fortified yogurt & $131.49 \pm 5.44 a$ & $114.82 \pm 5.50 a$ & $15.39 \pm 2.04 a$ & $0.124 \pm 0.002 b$ \\
\hline
\end{tabular}

(g/w): gram/week, FER feed efficiency ratio

Mean values in each column having different letters ( $a, b, c$ and $d)$ are significantly different at $p<0.05$ 
lipase, trypsin and amylase levels [40]. Aflatoxin is known to impair protein biosynthesis by forming adducts with DNA, RNA and proteins, to inhibit RNA synthesis and DNA-dependent RNA polymerase activity and to cause degranulation of the endoplasmic reticulum. A reduction in protein content could also be caused due to increased hepatocellular necrosis. Other investigators have reported a decrease in protein concentration in the skeletal muscle, heart, liver and kidneys of aflatoxin-fed animals $[41,42]$. Our results agreed with previous studies that reported that dietary exposure to AFB1 and other aflatoxins leads to less weight gain in both chickens and turkeys. A decreased efficiency of nutrient usage contributes to the impaired growth during aflatoxicosis. AFB1 dampens food conversion, causing poultry to require more feed to produce muscle and eggs $[43,44]$. The body weight of the rats that declined due to the aflatoxin recovered after treatment with selenium-fortified yogurt. This is likely related to the composition of yogurt including proteins, fat, lactose and biogenic metabolites such as vitamins, peptides, oligosaccharides and organic acids $[45,46]$. A separate study in rats suggested that probiotic treatment prevented weight loss and reduced the hepatotoxic effects caused by a high dose of AFB1 by increasing the excretion of orally administered aflatoxin in faeces [47]. Selenium added to yogurt, regarded as a basic trace element essential for the normal growth and development of humans and animals and acting as antioxidant, improves nutritional results. As a component of selenoproteins, selenium has both structural and enzymatic functions, protects cell lipids from the harmful effects of reactive oxygen species and can minimize the production of hydrogen peroxide by aflatoxins [48].

The positive control group that consumed 3\% mixed nuts contaminated with aflatoxins showed significant increases in serum cholesterol, TG, LDLc and VLDLc and lower values of serum HDLc compared to the negative control group. Consumption of $3 \%$ pistachios, cashews, walnuts, almonds and hazelnuts contaminated with aflatoxins along with selenium-fortified yogurt led to significant decreases in serum cholesterol, TG, LDLc and VLDLc and higher values of serum HDLc compared to the positive control group. Consumption of seleniumfortified yogurt could somewhat normalize these values compared to the negative control group (Table 3).

Yogurt is recognized as a functional food, and its consumption correlates with a reduced risk of numerous cancers. Probiotic bacteria in yogurt, including lactobacilli and streptococci, can reduce serum cholesterol levels by metabolizing cholesterol and reducing its re-absorption in the gastrointestinal tract. Probiotics in yogurt can assimilate cholesterol by incorporating it into membranes and can deconjugate and precipitate bile acids, leading to excretion of free bile acids through the stool $[49,50]$. Selenium compounds play an important role in neutralizing and removing a variety of toxic substances from the body. Research has shown a relationship between selenium deficiency in humans and an increased cancer risk. Selenium inactivates aflatoxins, thus protecting the body from their carcinogenic effects [51].

The positive control rat group showed significant increases in serum total lipids, phospholipids, $\mathrm{CHO} /$ HDLc and LDLc/HDLc compared to the negative control rat group. Rats that consumed 3\% pistachios, cashews, walnuts, almonds and hazelnuts contaminated with aflatoxins along with selenium-fortified yogurt showed significant decreases in serum total lipids, phospholipids and atherogenic indexes (CHO/HDLc and LDLc/HDLc) compared to the positive control group. When compared to the negative control group, consumption of pistachios, cashews and almonds contaminated with aflatoxins and selenium-fortified yogurt produced significant increases in serum phospholipids and atherogenic index values (LDLc/HDLc) and insignificant increases in total lipids

Table 3 Serum lipids profile of the experimental rat groups

\begin{tabular}{|c|c|c|c|c|c|}
\hline \multicolumn{5}{|l|}{ Groups } & $\operatorname{VLDLc}(\mathrm{mg} / \mathrm{dl})$ \\
\hline Negative control consumed 3\% mixed fresh nuts & $95.17 \pm 8.67 \mathrm{bc}$ & $69.41 \pm 5.25 b c$ & $36.86 \pm 5.41 a$ & $44.43 \pm 4.56 \mathrm{~d}$ & $13.88 \pm 1.68 b c$ \\
\hline $\begin{array}{l}\text { Positive control consumed } 3 \% \text { mixed nuts contaminated } \\
\text { with aflatoxins }\end{array}$ & $167.25 \pm 15.24 a$ & $90.31 \pm 8.40 \mathrm{a}$ & $24.31 \pm 3.23 c$ & $124.34 \pm 13.81 a$ & $18.06 \pm 1.45 a$ \\
\hline \multicolumn{6}{|c|}{ Rat groups consumed 3\% pistachios, cashews, walnuts, almonds and hazelnuts contaminated with aflatoxins } \\
\hline Pistachios with selenium-fortified yogurt & $112.45 \pm 11.22 b$ & $75.55 \pm 3.44 b$ & $32.98 \pm 3.50 a$ & $64.36 \pm 5.99 b$ & $15.11 \pm 1.33 b$ \\
\hline Cashews with selenium-fortified yogurt & $109.60 \pm 12.75 b$ & $72.41 \pm 5.73 b$ & $33.65 \pm 3.24 a$ & $61.47 \pm 8.17 b$ & $14.48 \pm 1.50 \mathrm{~b}$ \\
\hline Walnuts with selenium-fortified yogurt & $113.76 \pm 10.64 b$ & $74.01 \pm 4.55 b$ & $31.99 \pm 4.03 a b$ & $66.9 \pm 6.78 b$ & $14.80 \pm 1.12 b$ \\
\hline Almonds with selenium-fortified yogurt & $103.80 \pm 11.14 b$ & $73.61 \pm 7.03 b$ & $34.11 \pm 2.71 \mathrm{a}$ & $54.97 \pm 6.40 \mathrm{bc}$ & $14.72 \pm 1.57 b$ \\
\hline Hazelnuts with selenium-fortified yogurt & $101.70 \pm 10.14 b$ & $70.14 \pm 5.11 b$ & $35.65 \pm 4.81 \mathrm{a}$ & $52.02 \pm 5.71 b c$ & $14.03 \pm 1.35 b$ \\
\hline
\end{tabular}

Mean values in each column having different letters ( $a, b, c$ and $d)$ are significantly different at $p<0.05$ 
and $\mathrm{CHO} / \mathrm{HDLc}$. Consumption of walnuts contaminated with aflatoxins along with selenium-fortified yogurt produced insignificant differences in serum total lipids, phospholipids and atherogenic index (CHO/HDLc) and a significant increase in LDLc/HDLc. Consumption of hazelnuts contaminated with aflatoxins along with selenium-fortified yogurt produced insignificant differences in serum total lipids and atherogenic indexes $(\mathrm{CHO} /$ HDLc and LDLc/HDLc) and a significant increase in serum phospholipids (Table 4).

Our results were in agreement with published reports $[10,52,53]$. Probiotic bacteria in yogurt can inhibit peroxidation of lipids through scavenging reactive oxygen radicals, such as hydroxyl radicals or hydrogen peroxide, and can produce antioxidant factors, such as superoxide dismutase or glutathione, as well as various peptides derived from $\alpha$-lactalbumin, $\beta$-lactoglobulin and $\alpha$-casein. It has been reported that some lactic acid bacteria in yogurt can remove or have protective effects against AFB1. Some relevant studies have demonstrated that lactobacilli can inhibit the production of aflatoxin as well as the growth of Aspergillus spp. Researchers have also analysed AFB1 removal by lactobacilli in vitro and noted that lactobacilli could rapidly remove AFB1 with a removal rate of approximately $50-80 \%$ [54, 55]. Ingestion yogurt regulated the expression of sterol regulatory element binding protein, other lipogenic enzymes and $\beta$-oxidation-related genes, which produce enzymes that are involved in the catabolism of fatty acids cholesterol in the rat liver. Selenium improves the activity of the selenoenzyme. Selenium is also present in the active centre of glutathione peroxidase, an antioxidant enzyme, which protects lipid membranes and macromolecules from oxidative damage produced by peroxides. Furthermore, glutathione peroxidase has the ability to counteract free radicals and protect the structure and function of proteins, DNA and chromosomes against oxidation [56].
The positive control group showed significant increases in liver cholesterol and total lipids and significant decreases in liver TG and glycogen compared to the negative control group. Consumption of $3 \%$ pistachios, cashews, walnuts, almonds and hazelnuts contaminated with aflatoxins along with selenium-fortified yogurt resulted in significant decreases in liver cholesterol and total lipids and significant increases in liver TG and glycogen compared to the positive control group, which consumed $3 \%$ mixed nuts contaminated with aflatoxins, and produced values within the expected range established by the negative control group (Table 5).

Aflatoxins cause food poisoning, and acute doses are responsible for liver and kidney damage and, potentially, hepatocarcinoma. Exposure to aflatoxins can lead to liver injuries, liver fibrosis and hepatocellular carcinoma and therefore poses a considerable health risk for humans and livestock [57]. AFB1 exposure causes alterations in metabolic processes, such as glycogenolysis/ glycolysis and phospholipidation, and changes in amino acid transportation. AFB1 exposure can also indirectly result in damage to cell membranes and ultimately lead to cell death [58]. AFB1 exposure also causes other metabolic alterations, especially in the metabolism of lipids, choline, nucleic acids and cholesterol. Aflatoxins cause oxidative stress by increasing lipid peroxidation and decreasing enzymatic and non-enzymatic antioxidants in aflatoxin-treated animals [59, 60]. Yogurt containing lactic acid bacteria (lactobacilli and streptococci) improves liver efficiency by lowering bacterial translocation and by stimulating the effects of intestinal mucosa and altering intestinal microflora that influence the intestinal barrier [61]. These yogurt bacteria inhibited the peroxidation of lipids through scavenging reactive oxygen species, such as hydroxyl radicals or hydrogen peroxide [52].

Table 6 shows the levels of haemoglobin, PCV and glucose in the control and experimental rat groups.

Table 4 Serum T. lipids, phospholipids, CHO/HDLc and LDLc/HDLc in the experimental rat groups

\begin{tabular}{|c|c|c|c|c|}
\hline Variables & T. lipids (mg/dl) & Phospholipids (mg/dl) & CHO/HDLc & LDLc/HDLc \\
\hline \multicolumn{5}{|l|}{ Groups } \\
\hline Negative control consumed $3 \%$ mixed safe nuts & $322.17 \pm 99.76 b$ & $157.59 \pm 11.58 c$ & $2.58 \pm 0.56 \mathrm{bc}$ & $1.20 \pm 0.23 c$ \\
\hline Positive control consumed $3 \%$ mixed nuts contaminated with aflatoxins & $578.41 \pm 141.51 a$ & $320.85 \pm 95.88 a$ & $6.87 \pm 1.22 \mathrm{a}$ & $5.11 \pm 1.09 a$ \\
\hline \multicolumn{5}{|c|}{ Rat groups consumed 3\% pistachios, cashews, walnuts, almonds and hazelnuts contaminated with aflatoxins } \\
\hline Pistachios with selenium-fortified yogurt & $360.71 \pm 101.21 b$ & $172.71 \pm 17.89 b$ & $3.40 \pm 0.62 b$ & $1.95 \pm 0.22 b$ \\
\hline Cashews with selenium-fortified yogurt & $350.45 \pm 111.13 b$ & $168.44 \pm 15.90 b$ & $3.25 \pm 0.55 b$ & $1.82 \pm 0.33 b$ \\
\hline Walnuts with selenium-fortified yogurt & $345.21 \pm 99.61 b$ & $157.44 \pm 14.45 c$ & $3.55 \pm 0.57 b$ & $1.98 \pm 0.45 b$ \\
\hline Almonds with selenium-fortified yogurt & $355.11 \pm 109.51 b$ & $177.71 \pm 18.87 \mathrm{~b}$ & $3.04 \pm 0.70 b c$ & $1.61 \pm 0.50 b$ \\
\hline Hazelnuts with selenium-fortified yogurt & $343.66 \pm 105.64 b$ & $171.82 \pm 18.03 b$ & $2.85 \pm 0.61 b c$ & $1.45 \pm 0.43 b c$ \\
\hline
\end{tabular}

Mean values in each column having different letters ( $a, b, c$ and $d$ ) are significantly different at $p<0.05$ 
Table 5 Liver cholesterol, T. lipids, TG and glycogen in the experimental rat groups

\begin{tabular}{lcccc}
\hline $\begin{array}{llll}\text { Variables } \\
\text { Groups }\end{array}$ & CHO (mg/g) & T. lipid (mg/g) & TG (mg/g) & Glycogen (mg/100 g) \\
\hline Negative control consumed 3\% mixed safe nuts & & & \\
Positive control consumed 3\% mixed nuts contaminated with aflatoxins & $6.86 \pm 0.91 \mathrm{a}$ & $59.51 \pm 8.55 \mathrm{a}$ & $2.19 \pm 0.23 \mathrm{~b}$ & $3.11 \pm 0.36 \mathrm{~b}$ \\
Rat groups consumed 3\% pistachios, cashews, walnuts, almonds and hazelnuts contaminated with aflatoxins & & & \\
Pistachios with selenium-fortified yogurt & $4.07 \pm 0.64 \mathrm{~b}$ & $39.95 \pm 4.77 \mathrm{~b}$ & $3.24 \pm 0.25 \mathrm{a}$ & $4.99 \pm 0.50 \mathrm{a}$ \\
Cashews with selenium-fortified yogurt & $4.80 \pm 0.65 \mathrm{~b}$ & $38.55 \pm 4.44 \mathrm{~b}$ & $3.35 \pm 0.25 \mathrm{a}$ & $4.83 \pm 0.55 \mathrm{a}$ \\
Walnuts with selenium-fortified yogurt & $4.96 \pm 0.66 \mathrm{~b}$ & $36.97 \pm 4.62 \mathrm{~b}$ & $3.39 \pm 0.21 \mathrm{a}$ & $4.96 \pm 0.56 \mathrm{a}$ \\
Almonds with selenium-fortified yogurt & $4.06 \pm 0.76 \mathrm{~b}$ & $37.79 \pm 4.53 \mathrm{~b}$ & $3.30 \pm 0.33 \mathrm{a}$ & $4.88 \pm 0.88 \mathrm{a}$ \\
Hazelnuts with selenium-fortified yogurt & $4.91 \pm 0.76 \mathrm{~b}$ & $35.92 \pm 4.69 \mathrm{~b}$ & $3.44 \pm 0.43 \mathrm{a}$ & $4.90 \pm 0.95 \mathrm{a}$ \\
\hline
\end{tabular}

Mean values in each column having different letters ( $a, b, c$ and $d$ ) are significantly different at $p<0.05$

Decreased haemoglobin and PCV and increased levels of glucose were observed in the positive control rat group that consumed 3\% mixed nuts contaminated with aflatoxins. Consumption of $3 \%$ pistachios, cashews, walnuts, almonds and hazelnuts contaminated with aflatoxins along with selenium-fortified yogurt produced significant increases in haemoglobin and PCV and a significant decrease in glucose compared to the positive control group, with this values appearing within the range of those of the negative control group.

The decreased haemoglobin and PCV indicate the severity of hepatic damage induced by aflatoxins. The decrease in haemoglobin levels might be due to increased catabolism and degradation of haemoglobin into bilirubin. The reduction in HG content could be related to decreases in red blood cell numbers, which is indicative of anaemia [62]. Our observations suggested that one of the consequences of aflatoxin exposure is accelerated rates of glycogenolysis and glycolysis. Rats exposed to aflatoxins exhibited significantly reduced hepatic glucose/glycogen levels and elevated plasma glucose. Previous investigations have also reported increased glucose utilization and that several enzymes metabolizing glycogen, such as glucose 6-phosphate dehydrogenase, were upregulated following AFB1 exposure [60]. In addition of nutritional values of selenium-fortified yogurt, selenium conferred protection against AFB1-induced testicular toxicity and effectively protected the liver and spleen against AFB1induced toxicity. In previous studies, dietary selenium protected chicks from AFB1-induced liver injury, potentially through the synergistic actions of inhibition of the pivotal CYP450 isozyme-mediated activation of AFB1 to toxic $\mathrm{AFBO}$ and the increased antioxidant capacities caused by upregulation of selenoprotein genes coding for antioxidant proteins. Low selenium status can upregulate the activity of hepatic heme oxygenase-1, which catalyses the initial step of heme catabolism and reduces heme to biliverdin, carbon monoxide and free divalent iron [42, 63]. Thus, selenium could potentially play a role in the anaemia of chronic inflammation through its relationship with the upregulation of interleukin- 6 that implicated in the upregulation of the iron regulatory hepcidin hormone that blocks iron absorption in the gut and iron release from macrophages and the liver [64]. Lactic acid bacteria have shown great ability to bind aflatoxin in contaminated medium. It has been suggested that a physical union through an adhesion of aflatoxin to bacterial cell wall components (polysaccharides and peptidoglycans)

Table 6 Blood HG, PCV and glucose in the experimental rat groups

\begin{tabular}{lccc}
\hline $\begin{array}{l}\text { Variables } \\
\text { Groups }\end{array}$ & HG (g/dl) & PCV \% & Glucose (mg/dl) \\
\hline Negative control consumed 3\% mixed safe nuts & $13.98 \pm 1.89 \mathrm{a}$ & $38.42 \pm 4.53 \mathrm{a}$ & $95.85 \pm 5.99 \mathrm{c}$ \\
Positive control consumed 3\% mixed nuts contaminated with aflatoxins & $10.99 \pm 1.25 \mathrm{c}$ & $27.53 \pm 2.60 \mathrm{c}$ & $149.06 \pm 10.37 \mathrm{a}$ \\
Rat groups consumed 3\% pistachios, cashews, walnuts, almonds and hazelnuts contaminated with aflatoxins & & \\
Pistachios with selenium-fortified yogurt & $12.65 \pm 1.26 \mathrm{ab}$ & $34.38 \pm 4.59 \mathrm{ab}$ & $104.63 \pm 13.29 \mathrm{bc}$ \\
Cashews with selenium-fortified yogurt & $12.79 \pm 1.33 \mathrm{ab}$ & $35.08 \pm 4.87 \mathrm{ab}$ & $105.76 \pm 11.55 \mathrm{bc}$ \\
Walnuts with selenium-fortified yogurt & $12.45 \pm 1.34 \mathrm{ab}$ & $34.56 \pm 4.50 \mathrm{ab}$ & $107.09 \pm 12.11 \mathrm{bc}$ \\
Almonds with selenium-fortified yogurt & $12.77 \pm 1.55 \mathrm{~b}$ & $33.98 \pm 4.08 \mathrm{ab}$ & $106.70 \pm 11.29 \mathrm{bc}$ \\
Hazelnuts with selenium-fortified yogurt & $12.88 \pm 1.63 \mathrm{ab}$ & $34.70 \pm 4.80 \mathrm{ab}$ & $110.03 \pm 13.28 \mathrm{bc}$ \\
\hline
\end{tabular}

Mean values in each column having different letters (a, b, $c$ and $d)$ are significantly different at $p<0.05$ 
might be responsible for reducing the bioavailability of mycotoxins, instead of covalent binding or degradation [65].

\section{Histopathological results}

Microscopically, the liver of rats from the negative control group that consumed 3\% mixed safe fresh nuts had the expected histological structure of hepatic lobules (Fig. 1a). In comparison, the livers of the positive control group that consumed 3\% mixed nuts contaminated with aflatoxins showed congestion of hepatoportal blood vessels, portal oedema and focal hepatic necrosis associated with leucocytic cell infiltration (Fig. 1b). Consumption of selenium-fortified yogurt by rat groups that consumed pistachios, cashews, walnuts, almonds and hazelnuts contaminated with aflatoxins resulted in liver histological structures with featured between those of healthy and injured cells. Livers of rats that consumed 3\% pistachios contaminated with aflatoxins and seleniumfortified yogurt showed slight congestion of the central vein (Fig. 1c). However, livers from rats that consumed $3 \%$ cashews and walnuts contaminated with aflatoxins appeared healthy with no histopathological changes (Figs. 1d, e). The rats that consumed 3\% almonds contaminated with aflatoxins had vacuolations of hepatocytes (Fig. 1f), but rats that consumed 3\% hazelnuts only showed mild Kupffer cell activation (Fig. 1g).

The kidneys filter and remove toxins from the body. Hence, a histopathological study of the kidneys was undertaken to evaluate the efficacy of selenium-fortified yogurt in ameliorating the harmful effects of aflatoxin. Microscopic examination of the kidneys from the negative control group that consumed 3\% mixed fresh nuts showed the expected histological structure of renal parenchyma (Fig. 2a). Kidneys from the positive control group that consumed 3\% mixed nuts contaminated with aflatoxins showed chronic interstitial nephritis and periglomerular fibroblast proliferation (Fig. 2b). Kidneys from rats that consumed 3\% pistachios contaminated with aflatoxins and selenium-fortified yogurt showed a slight dilatation of renal tubules (Fig. 2c), while kidneys from rats that consumed 3\% cashews, walnuts, almonds and hazelnuts contaminated with aflatoxins and selenium-fortified yogurt showed the expected normal histological structure of renal parenchyma (Figure $2 \mathrm{~d}-\mathrm{g}$ ).

The histological results from this current study confirmed the biochemical analysis and indicated that consumption of mixed nuts contaminated with aflatoxins induces severe histological changes in the liver and kidneys of rats, as previously documented [5, 66]. Acute aflatoxin poisoning caused hepatocellular necrosis and derangement of hepatic functions. Subacute or chronic aflatoxicosis caused changes to fatty portions of the liver, enlargement of the gall bladder and periportal fibrosis with proliferative changes in the bile duct epithelium [67, 68]. The significant recovery of hepatic and kidney tissues through consumption of selenium-fortified yogurt is consistent with previous results in mice [69]. The improvements in the liver tissues have also already been seen in mice orally administered with viable $L$. plantarum C88 through the increase of faecal AFB1 excretion, which reversed deficits in antioxidant defence systems and regulated the metabolism of AFB1 [70].

\section{Conclusions}

Consumption of nuts stored in bad conditions leads to aflatoxin toxicity, primarily in the liver and kidneys. Consumption of selenium-fortified yogurt can successfully protect against this aflatoxin toxicity. Further researches and studies must be undertaken systematically and constantly to better understand the in vivo mechanisms by using other types of food which reduce aflatoxin toxicity and its side effects. Overall, the application of probiotic bacteria and selenium to improve safety in the food 

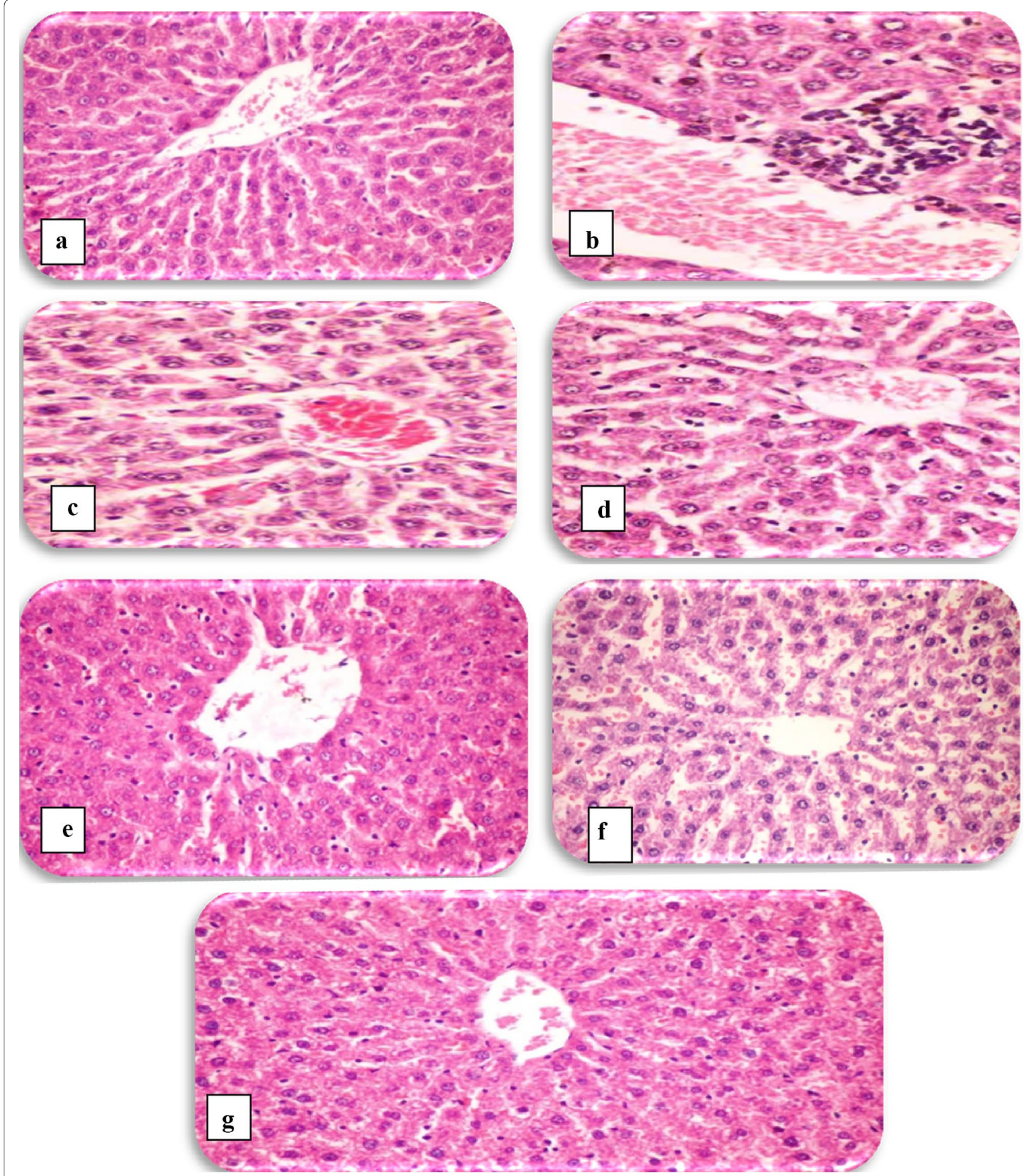

Fig. 1 Histological structure of the liver of the negative control group (a), in the positive control group (b), of the pistachio with selenium-fortified yogurt group $(\mathbf{c})$, of the cashews with selenium-fortified yogurt group $(\mathbf{d})$, of the walnuts with selenium-fortified yogurt group (e), of the almonds with selenium-fortified yogurt group $(\mathbf{f})$ and of the hazelnuts with selenium-fortified yogurt group ( $\mathbf{g})$ 

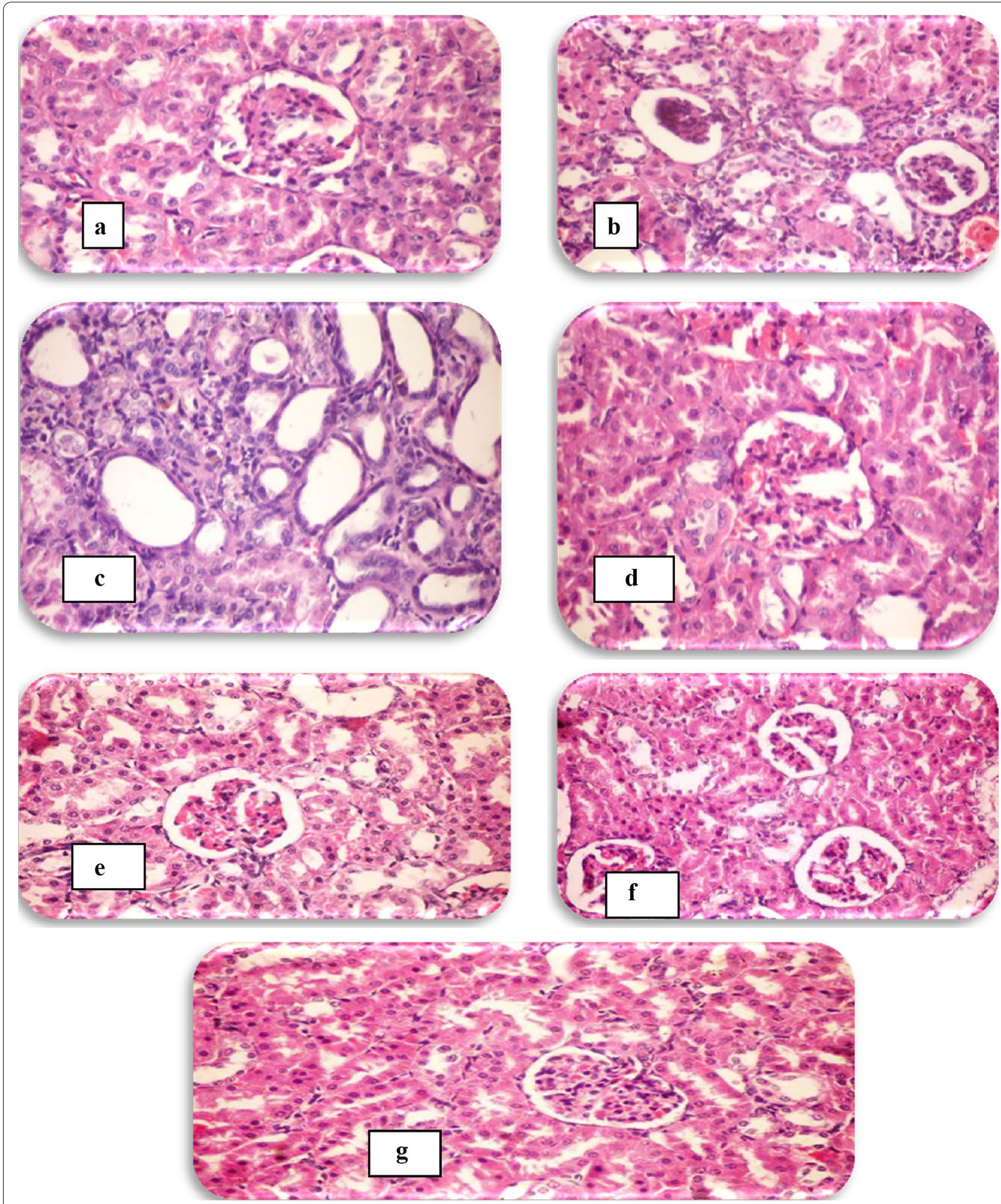

Fig. 2 Histological structure of the kidneys of the negative control group (a), of the positive control group (b), of the pistachio with seleniumfortified yogurt group (c), of the cashews with selenium-fortified yogurt group (d), of the walnuts with selenium-fortified yogurt rat group (e), of almonds with selenium-fortified yogurt group (f) and of the hazelnuts with selenium-fortified yogurt group ( $\mathbf{g}$ ) 
industry is a viable, vital therapeutic approach. Therefore, it is recommended to consume fresh nuts along with selenium-fortified yogurt to reduce the effects of aflatoxins.

\section{Abbreviations}

AF: aflatoxins; FER: feed efficiency ratio; CHO: serum cholesterol; TG: triglycerides; HDLc: high-density lipoprotein cholesterol; T. lipids: total lipids; VLDLc: very low-density lipoprotein cholesterol; LDLC: low-density lipoprotein cholesterol; HG: haemoglobin; PCV: packed cell volume.

\section{Authors' contributions}

AMA conceived and designed the research, collected and analysed the data and wrote the manuscript. Additionally, she conceived the study, followed up the field work, supervised the animal experiments with technical specialists and reviewed and made editorial comments on the draft of the manuscript. In addition, she was involved in proof reading and editorial comments on the draft of the manuscript. The author read and approved the final manuscript.

\section{Acknowledgements}

The author (Amnah Mohammed ALsuhaibani) records her profound gratitude to Princess Nourah Bint Abdulrahman University for its financial and moral support in accomplishing this research paper.

\section{Competing interests}

The author declares that she has no competing interests.

\section{Availability of data and materials}

The dataset supporting the conclusions of this article is included within top of the article.

\section{Consent for publication}

Not applicable.

\section{Ethics approval and consent to participate}

Ethical guidelines were maintained in animal handling during the study, and permission was obtained from the relevant department

\section{Funding}

Princess Nourah Bint Abdulrahman University, Nutrition and Food Sciences Department.

\section{Publisher's Note}

Springer Nature remains neutral with regard to jurisdictional claims in published maps and institutional affiliations.

Received: 5 January 2018 Accepted: 15 February 2018

Published online: 21 June 2018

\section{References}

1. Bennett JW, Klich M. Mycotoxins. Clin Microbiol Rev. 2003;16:497-516.

2. Rawal S, Kim JE, Coulombe R Jr. Aflatoxin B1 in poultry: toxicology, metabolism and prevention. Res Vet Sci. 2010;89:325-31.

3. Williams JH, Phillips TD, Jolly PE, Stiles JK, Jolly CM, Aggarwal D. Human aflatoxicosis in developing countries: a review of toxicology, exposure, potential health consequences, and interventions. Am J Clin Nutr. 2004;80:1106-22.

4. Zhang L, Ye Y, An Y, Tian Y, Wang Y, Tang H. Systems responses of rats to aflatoxin B1 exposure revealed with metabonomic changes in multiple biological matrices. J Proteome Res. 2011;10:614-23.

5. Wogan GN, Kensler TW, Groopman JD. Present and future directions of translational research on aflatoxin and hepatocellular carcinoma. A review. Food Addit Contam A Chem Anal Control Expo Risk Assess. 2012;29:249-57.
6. Bedard LL, Massey TE. Aflatoxin B1-induced DNA damage and its repair. Cancer Lett. 2006:241:174-83.

7. Cotty PJ, Jaime-Garcia R. Influences of climate on aflatoxin producing fungi and aflatoxin contamination. Int J Food Microbiol. 2007;1 19:109-15.

8. Wild CP, Montesano R. A model of interaction: aflatoxins and hepatitis viruses in liver cancer aetiology and prevention. Cancer Lett. 2009:286:22-8

9. Spanhaak S, Havenaar R, Schaafsma G. The effect of consumption of milk fermented by Lactobacillus casei strain Shirota on the intestinal microflora and immune parameters in humans. Eur J Clin Nutr. 1998;52:899-907.

10. Fitzgerald RJ, Murray BA. Bioactive peptides and lactic fermentations. Int J Dairy Technol. 2006;59:118-25.

11. Keszei AP, Schouten LJ, Goldbohm RA, van den Brandt PA. Dairy intake and the risk of bladder cancer in the Netherlands cohort study on diet and cancer. Am J Epidemiol. 2010;171:436-46.

12. Knasmuller S, Steinkellner H, Hirschl AM, Rabot S, Nobis EC, Kassie F. Impact of bacteria in dairy products and of the intestinal microflora on the genotoxic and carcinogenic effects of heterocyclic aromatic amines. Mutat Res. 2001;480-481:129-38.

13. Kato I, Tanaka K, Yokokura T. Lactic acid bacterium potently induces the production of interleukin-12 and interferon-gamma by mouse splenocytes. Int J Immunopharmacol. 1999;21:121-31.

14. Lim BK, Mahendran R, Lee YK, Bay BH. Chemopreventive effect of Lactobacillus rhamnosus on growth of a subcutaneously implanted bladder cancer cell line in the mouse. Jpn J Cancer Res. 2002;93:36-41.

15. Sangwan $S$, Singh R. Therapeutic effects of probiotic fermented milk (LGG and $L$ casei NCDC 19) on progression of type 2 diabetes. J Innov Biol. 2014;1:78-83.

16. Kukreja R, Khan A. Effect of selenium deficiency and its supplementation on DTH response, antibody forming cells and antibody titre. Indian J Exp Biol. 1998;36:203-5.

17. Gill H, Walker G. Selenium, immune function and resistance to viral infections. Nutr Diet. 2008:65:S41-7.

18. Jakhar KK, Sadana JR. Sequential pathology of experimental aflatoxicosis in quail and the effect of selenium supplementation in modifying the disease process. Mycopathologia. 2004;157:99-109.

19. Shi CY, Chua SC, Lee HP, Ong CN. Inhibition of aflatoxin B1-DNA binding and adduct formation by selenium in rats. Cancer Lett. 1994;82:203-8.

20. Uysal H, Agar G. Selenium protective activity against aflatoxin B1 adverse affects on Drosophila melanogaster. Braz Arch Biol Technol. 2005;48:227-33.

21. Wang F, Shu G, Peng X, Fang J, Chen K, Cui H, et al. Protective effects of sodium selenite against aflatoxin B1-induced oxidative stress and apoptosis in broiler spleen. Int J Environ Res Public Health. 2013:10:2834-44.

22. Anonymous. Enzyme immunoassay for the quantitative analysis of aflatoxins. Aflatoxin Total Art. No. R-4701. Darmstadt: R-Biopharm GmbH; 2004.

23. Senyuva HZ, Gilbert J. Immunoaffinity column cleanup with liquid chromatography using post-column bromination for determination of aflatoxins in hazelnut paste: interlaboratory study. J AOAC Int. 2005:88:526-35.

24. Second Report of American Institute of Nutrition. Nutrient requirement of laboratory animals. J Nutr. 1980;110:1726-32.

25. Tamime AY, Robinson RK. Yoghurt-science and technology. Cambridge: Woodhead Publishers; 1999

26. Allain CC, Poon LS, Chan CS, Richmond W, Fu PC. Enzymatic determination of total serum cholesterol. Clin Chem. 1974;20:470-5.

27. Bucolo G, David H. Quantitative determination of serum triglycerides by the use of enzymes. Clin Chem. 1973;19:476-82.

28. Kostner GM. Enzymatic determination of cholesterol in high-density lipoprotein fractions prepared by polyanion precipitation. Clin Chem. 1976;22:695.

29. Fruchart GG. LDL-cholesterol determination after separation of low density lipoprotein. Revue Française des Laboratoires. 1982;103:7-117.

30. Coles EH. Veterinary clinical pathology. Philadelphia: Saunders Company; 1974

31. Nakai VK, Rocha LO, Gonçalez E, Fonseca H, Ortega EMM, Corrêa B. Distribution of fungi and aflatoxins in a stored peanut variety. Food Chem. 2008;106:285-90.

32. Leong Y-H, Ismail N, Latif AA, Ahmad R. Aflatoxin occurrence in nuts and commercial nutty products in Malaysia. Food Control. 2010;21:334-8. 
33. Artimage GY, Berry WG. Statistical methods. 7th ed. Ames: lowa Stata University Press; 1987

34. Mustapha A, Jiang T, Savaiano DA. Improvement of lactose digestion by humans following ingestion of unfermented acidophilus milk: influence of bile sensitivity, lactose transport, and acid tolerance of Lactobacillus acidophilus. J Dairy Sci. 1997;80:1537-45

35. Anderson JW, Gilliland SE. Effect of fermented milk (yogurt) containing Lactobacillus acidophilus L1 on serum cholesterol in hypercholesterolemic humans. J Am Coll Nutr. 1999;18:43-50.

36. Andrade S, Borges N. Effect of fermented milk containing Lactobacillus acidophilus and Bifidobacterium longum on plasma lipids of women with normal or moderately elevated cholesterol. J Dairy Res. 2009;76:469-74.

37. Yeung PS, Sanders ME, Kitts CL, Cano R, Tong PS. Species-specific identification of commercial probiotic strains. J Dairy Sci. 2002;85:1039-51.

38. Ostlie HM, Helland MH, Narvhus JA. Growth and metabolism of selected strains of probiotic bacteria in milk. Int J Food Microbiol. 2003;87:17-27.

39. Preston RJ, Williams GM. DNA-reactive carcinogens: mode of action and human cancer hazard. Crit Rev Toxicol. 2005:35:673-83.

40. Osborne DJ, Huff WE, Hamilton PB, Burmeister HR. Comparison of ochratoxin, aflatoxin, and T-2 toxin for their effects on selected parameters related to digestion and evidence for specific metabolism of carotenoids in chickens. Poult Sci. 1982:61:1646-52.

41. Abdel-Wahhab MA, Ahmed HH, Hagazi MM. Prevention of aflatoxin B1-initiated hepatotoxicity in rat by marine algae extracts. J Appl Toxicol. 2006;26:229-38.

42. Sun LH, Zhang NY, Zhu MK, Zhao L, Zhou JC, Qi DS. Prevention of aflatoxin B1 hepatoxicity by dietary selenium is associated with inhibition of cytochrome P450 isozymes and up-regulation of 6 selenoprotein genes in chick liver. J Nutr. 2016;146:655-61.

43. Pandey I, Chauhan SS. Studies on production performance and toxin residues in tissues and eggs of layer chickens fed on diets with various concentrations of aflatoxin AFB1. Br Poult Sci. 2007;48:713-23.

44. Lee JT, Jessen KA, Beltran R, StarkI V, Schatzmayr G, Borutova R, et al. Mycotoxin-contaminated diets and deactivating compound in laying hens: 1. Effects on performance characteristics and relative organ weight. Poult Sci. 2012;91:2089-95.

45. Santosa S, Farnworth E, Jones PJ. Probiotics and their potential health claims. Nutr Rev. 2006;64:265-74.

46. Junaid M, Javed I, Abdullah M, Gulzar M, Younas U, Nasir J, et al. Development and quality assessment of flavored probiotic acidophilus milk. J Anim Plant Sci. 2013;23:1342-6.

47. Gratz $S$, Täubel $M$, Juvonen $R O$, Viluksela $M$, Turner PC, Mykkänen $H$, et al. Lactobacillus rhamnosus strain GG modulates intestinal absorption, fecal excretion, and toxicity of aflatoxin B(1) in rats. Appl Environ Microbiol. 2006;72:7398-400.

48. Rayman MP. The importance of selenium to human health. Lancet. 2000;356:233-41.

49. Agerholm-Larsen L, Raben A, Haulrik N, Hansen AS, Manders M, Astrup A. Effect of 8 week intake of probiotic milk products on risk factors for cardiovascular diseases. Eur J Clin Nutr. 2000;54:288-97.

50. Pereira DI, Gibson GR. Cholesterol assimilation by lactic acid bacteria and bifidobacteria isolated from the human gut. Appl Environ Microbiol. 2002:68:4689-93.

51. Debski B, Zachara B, Wasowicz W. Attempts to evaluate selenium level in Poland and its effect on human and animal health. Folia Universitas Agriculturae Stetinensis Zootechnica. 2001;224:31-8.

52. Lin MY, Yen CL. Antioxidative ability of lactic acid bacteria. J Agric Food Chem. 1999;47:1460-6.

53. Kiessling G, Schneider J, Jahreis G. Long-term consumption of fermented dairy products over 6 months increases HDL cholesterol. Eur J Clin Nutr. 2002:56:843-9.
54. Chang I, Kim JD. Inhibition of aflatoxin production of Aspergillus flavus by Lactobacillus casei. Mycobiology. 2007;35:76-81.

55. Gerbaldo GA, Barberis C, Pascual L, Dalcero A, Barberis L. Antifungal activity of two Lactobacillus strains with potential probiotic properties. FEMS Microbiol Lett. 2012:332:27-33.

56. Akhtar MS, Farooq AA, Mushtaq M. Serum concentrations of copper, iron, zinc and selenium in cyclic and anoestrus Nili-Ravi buffaloes kept under farm conditions. Pak Vet J. 2009;29:47-8.

57. Wild CP, Hall AJ. Primary prevention of hepatocellular carcinoma in developing countries. Mutat Res. 2000;462:381-93.

58. Diaz DE. A review on the use of mycotoxin sequestering agents in agricultural livestock production. In: Siantar DP, Trucksess MW, Scott PM, editors. Food contaminants: mycotoxins and food allergens. Washington: American Chemical Society; 2008. p. 125-50.

59. Rastogi R, Srivastava AK, Rastogi AK. Long term effect of aflatoxin B(1) on lipid peroxidation in rat liver and kidney: effect of picroliv and silymarin. Phytother Res. 2001;15:307-10.

60. Carvajal M. Aflatoxin-DNA adducts as biomarkers of cancer: nature, formation, kinds of AF-DNA adducts, methodology, effects and control. In: Siantar DP, Trucksess MW, Scott PM, editors. Food contaminants: mycotoxins and food allergens. Washington: American Chemical Society; 2000. p. 13-55.

61. Adawi D, Ahrne S, Molin G. Effects of different probiotic strains of Lactobacillus and Bifidobacterium on bacterial translocation and liver injury in an acute liver injury model. Int J Food Microbiol. 2001;70:213-20.

62. Mohiuddin S, Reddy MV, Reddy MM, Ramakrishna K. Studies on phagocytic activity and haematological changes in aflatoxicosis in poultry. Indian Vet J. 1986;63:442-5.

63. Cao Z, Shao B, Xu F, Liu Y, Li Y, Zhu Y. Protective effect of selenium on aflatoxin B1-induced testicular toxicity in mice. Biol Trace Elem Res. 2017;180:233-8.

64. Roy CN, Andrews NC. Anemia of inflammation: the hepcidin link. Curr Opin Hematol. 2005;12(2):107-11.

65. Elsanhoty RM, Salam SA, Ramadan MF, Badr FH. Detoxification of aflatoxin $\mathrm{M} 1$ in yoghurt using probiotics and lactic acid bacteria. Food Control. 2014:43:129-34.

66. Mayura K, Abdel-Wahhab MA, McKenzie KS, Sarr AB, Edwards JF, Naguib $K$, et al. Prevention of maternal and developmental toxicity in rats via dietary inclusion of common aflatoxin sorbents: potential for hidden risks. Toxicol Sci. 1998;41:175-82.

67. Weidenbörner M. Encyclopedia of food mycotoxins. Berlin: Springer; 2001.

68. Lakkawar AW, Chattopadhyay SK, Johri TS. Experimental aflatoxin B1 toxicosis in young rabbits-a clinical and patho-anatomical study. Slov Vet Res. 2004;41:73-81.

69. Hathout AS, Mohamed SR, El-Nekeety AA, Hassan NS, Aly SE, Abdel-Wahhab MA. Ability of Lactobacillus casei and Lactobacillus reuteri to protect against oxidative stress in rats fed aflatoxins-contaminated diet. Toxicon. 2011:58:179-86.

70. Huang L, Duan C, Zhao Y, Gao L, Niu C, Xu J, et al. Reduction of aflatoxin $\mathrm{B}(1)$ toxicity by Lactobacillus plantarum C88: a potential probiotic strain isolated from Chinese traditional fermented food "Tofu". PLOS ONE. 2017;12:e0170109.

\section{Submit your next manuscript to BioMed Central and we will help you at every step:}

- We accept pre-submission inquiries

- Our selector tool helps you to find the most relevant journal

- We provide round the clock customer support

- Convenient online submission

- Thorough peer review

- Inclusion in PubMed and all major indexing services

- Maximum visibility for your research

Submit your manuscript at www.biomedcentral com/submit

C BioMed Central 